\title{
THE SILENT EFFECT OF COVID-19 ON EMERGENCY DEPARTMENTS: HOW TO AVOID COMPLACENCY?
}

\author{
Mor Saban ${ }^{1}(1)$, Tal Shachar ${ }^{2}$ \\ ${ }^{1}$ The Faculty of Social Welfare and Health Sciences, University of Haifa, Israel \\ ${ }^{2}$ The Azrieli faculty of Medicine, Bar-llan University, Safed, Israel
}

KEY WORDS: complacency, COVID-19, emergency department, nursing, pandemic

Disaster Emerg Med J 2020; 5(4)

\section{THE EFFECT OF COVID-19 ON EMERGENCY DEPARTMENTS}

The course of pandemic morbidity is highly significant for health services and especially for emergency departments (EDs), which serve as a gateway for the severely ill. However, countries have followed remarkably different strategies in attempting to reduce health services loads.

The understanding of a temporarily calm period due to lack of symptoms preceding a dramatic increase in workload is of great importance for ED preparedness.

For example, the ED at the Rambam Health Care Campus, a tertiary hospital in northern Israel, experienced a smaller number $(\sim 30)$ of patient arrivals throughout the day compared with hundreds during similar periods in previous years.

Overall, in Israel, there is a significant decrease of $\sim 80 \%$ in ED admission rates since COVID-19 began to spread. This decrease may be related to patients' fears of infection alongside cost-benefit considerations of whether to visit the ED. Simultaneously, most of the moderate-to-severe COVID-19 patients in Israel are still in their early stages, identified as carriers of pneumonia and generally treated at community facilities. As their medical conditions worsen, a massive patient flow to the ED is expected, as was seen in Italy [1]. As described by Dr Daniele Macchini, an intensive care unit physician in Bergamo, near Milan, the EDs experienced a calm period, a respite with $50 \%$ occupancy. This period was characterized by medical staff uncertainty and slight indifference due to lower ED arrival rates. Then, one morning the first patient arrived; within a few hours, hundreds more did, leading Italian EDs and hospitals to a catastrophic state. As the doctor said: "I myself watched with some amazement the reorganization of the entire hospital in the past week... all this rapid transformation brought an atmosphere of silence and surreal emptiness to the corridors of the hospital that we did not yet understand, waiting for a war that was yet to begin and that many (including me) were not so sure would ever come with such ferocity."

In times of ED overload, with hundreds of complex patients simultaneously, the whole medical system becomes overwhelmed, and treatment necessarily becomes less efficient [2]. In addition, given the severe burdens, infection rates among staff members also increase. As health workers are at the front line of the COVID-19 outbreak response and as such are exposed to hazards that put them at risk of infection medical staff member infection is widespread globally [3]. For example, in Italy, France, and Spain, more than 60 health care professionals have died of the coronavirus, and thousands of others have had to self-isolate. In Spain alone, $14 \%$ of confirmed COVID-19 patients are medical professionals [4]. In the United States, the University of Washington Medicine began testing employees with symptoms at the beginning of March; $4.4 \%$ tested positive. In addition, at least 88 health care workers in Snohomish County have tested positive for the coronavirus, out of 1.300 total cases. In Yakima County, the numbers approximate 30\% [5]. 
This phenomenon can be explained by the load that directly increases both the rate and the risk of infection. Handling increasing numbers of patients reduces the attention to hygiene and sanitation rules required to manage the virus, as the main concern is survival and not prevention [6].

Implications for disease spread where clinician infections are not being captured may affect many aspects [7]. As health care systems, already crumbling under the strain of an expanding pandemic, they would not be able to handle the increased burden if medical professionals fall sick.

Simultaneously, a lack of resources and appropriate medical equipment aggravates the situation and emphasize the necessity of suitable organization and management of patients with diagnosed or suspected infection [8]. Imperial College London predicted that, by mid-June, even with social distancing and household quarantines, the demand for intensive care beds in the United States will exceed capacity [9].

Many concerns about capacity limits during the coronavirus pandemic have led hospitals and health care providers in the United States to appeal for donations of protective equipment, like masks, gloves, and gowns, to protect themselves from COVID-19 during what may turn out to be the early stages of the pandemic, knowing that sick health care providers will most likely worsen the crisis. It was estimated that with a combination of full protective equipment and the testing of $100 \%$ of symptomatic providers, they would be able to increase ICU capacity by an average of 1.824 patients per day over the first 200 days [10].

For example, nurses in Washington State and California said they have had to beg for N95 masks, which are thicker than surgical masks and block out much smaller particles, and have faced ridicule from colleagues when expressing concerns about catching the highly contagious virus. Others have complained about being pulled out of quarantine early to treat patients because of staff shortages [10].

\section{PRACTICAL SUGGESTIONS FOR IMPROVING PREPAREDNESS}

We believe that several activities that focus on ED nurses can improve preparedness for the COVID-19 pandemic.

1. Strengthening resilience and awareness among staff members - for example, embedding mindfulness intervention in the routine ED workflow [11].

2. Establishing knowledge and preparedness for the treatment of severely ill patients - preserving knowledge about operating mechanical ventilation equipment and managing patients with the life-threatening respiratory condition [12], all while performing simulations and practising the use of respiratory machines, addressing the machine's alarm, and identifying patients whose medical condition may worsen.

3. Ongoing practice by the entire hospital team - including the secretary team - in the identification and proper safety management of patients suspected of having COVID-19 [13].

4. Maintaining a journal club and updating it with the world's knowledge about the pandemic. Strengthening evidence-based knowledge among nursing staff on a daily basis before the start of each shift or on a weekly level.

5. Regularly maintaining emergency inventories, including robes, masks, and respirators, stored in a designated locked location until needed, in addition to maintaining supply lines through states of emergency [14].

6. Creating a staffing-based workflow chart [15], placing a "strong team" in key positions, and assembling organic teams in schedule shifts to prevent cross-infection and discontinuance of all working teams.

In conclusion, we believe that assimilating appropriate organizational practices with an emphasis on primary prevention in identifying the period of "calm before the storm" will strengthen staff preparedness, thereby improving care provided to patients and their families.

We all hope to overcome this pandemic with a minimal number of casualties and to become better prepared for future emergencies.

\section{Declarations}

The research has not been presented.

No financial support was received for this research. All authors attest to meeting the ICMJE.org authorship criteria.

None of the authors have any conflicts of interest.

\section{REFERENCES}

1. Benvenuto D, Giovanetti M, Ciccozzi A, et al. The 2019-new coronavirus epidemic: Evidence for virus evolution. J Med Virol. 2020; 92(4): 455-459, doi: 10.1002/jmv.25688, indexed in Pubmed: 31994738. 
2. Chen $Q$, Liang $M$, Li $Y$, et al. Mental health care for medical staff in China during the COVID-19 outbreak. Lancet Psychiatry. 2020; 7(4): e15-e16, doi: 10.1016/52215-0366(20)30078-X, indexed in Pubmed: 32085839.

3. Wieczorek K, Kulak K, Fajfer Z, et al. The scheme of treatment with an infected patient with COVID-19. Disaster and Emergency Medicine Journal. 2020, doi: 10.5603/demj.a2020.0021.

4. Okeleke UJ. A Study of the Results of Coronavirus (COVID-19) on the Nigerian Maritime Workers. , doi: 10.21467/preprints.176.

5. How Many Medical Workers Have Contracted COVID-19? States Lack Key Data. News | OPB n.d. https://www.opb.org/news/article/ coronavirus-covid-19-data-health-care-medical-workers-infection/ (accessed April 7 ; 2020).

6. Ranney ML, Griffeth V, Jha AK. Critical Supply Shortages - The Need for Ventilators and Personal Protective Equipment during the Covid-19 Pandemic. N Engl J Med. 2020; 382(18): e41, doi: 10.1056/ NEJMp2006141, indexed in Pubmed: 32212516.

7. Kulak K, Wieczorek K, Krupski A, et al. SARS-CoV-2 as a real threat for healthcare workers. Disaster and Emergency Medicine Journal. 2020, doi: 10.5603/demj.a2020.0018.

8. Smereka J, Szarpak L, Filipiak K. Modern medicine in COVID-19 era. Disaster and Emergency Medicine Journal. 2020, doi: 10.5603/demj. a2020.0012.
9. KRR G, KVR M, SSP P, et al. Non-Pharmaceutical Interventions (NPIs) to Reduce COVID-19 Mortality. SSRN Electronic Journal. , doi: 10.2139/ ssrn.3560688.

10. Grinols $E$, Henderson J. Why Government in Health Care? Health Care for Us All. : 91-108, doi: 10.1017/cb09780511626791.008.

11. Ducar DM, Penberthy JK, Schorling JB, et al. Mindfulness for healthcare providers fosters professional quality of life and mindful attention among emergency medical technicians. Explore (NY). 2020; 16(1): 61-68, doi: 10.1016/j.explore.2019.07.015, indexed in Pubmed: 31471216.

12. Pearce JM. A review of open source ventilators for COVID-19 and future pandemics. F1000Res. 2020; 9: 218, doi: 10.12688/f1000research.22942.2, indexed in Pubmed: 32411358.

13. Cheung JH, Ho L, Cheng J, et al. Staff safety during emergency airway management for COVID-19 in Hong Kong. The Lancet Respiratory Medicine. 2020; 8(4): e19, doi: 10.1016/s2213-2600(20)30084-9.

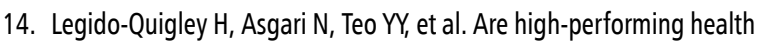
systems resilient against the COVID-19 epidemic? Lancet. 2020; 395(10227): 848-850, doi: 10.1016/S0140-6736(20)30551-1, indexed in Pubmed: 32151326.

15. Capanna F, Haydar A, McCarey C, et al. Preparing an obstetric unit in the heart of the epidemic strike of COVID-19: quick reorganization tips. J Matern Fetal Neonatal Med. 2020 [Epub ahead of print]: 1-7, doi: 10.1080/14767058.2020.1749258, indexed in Pubmed: 32223490. 